\title{
Videomapping arquitectónico: la tecnología al servicio de la renovación del espacio
}

\author{
Víctor-Antonio Lafuente Sánchez \\ Daniel López Bragado
}

Resumen

El videomapping arquitectónico es una alternativa a la percepción regular de los espacios urbanos, introduciendo la variable del movimiento en lo estático. Esta técnica, en creciente auge, lleva más allá el concepto de luz en el contexto de la arquitectura, hasta un nivel en el que las formas son definidas, modificadas o alteradas por operaciones de movimiento en un proceso global que incluye también efectos sonoros.

Esta contribución pretende investigar acerca de los dispositivos y técnicas utilizadas para realizar esta nueva forma de representación e intervención gráfica, analizando un gran número de proyectos diferentes, y buscando los elementos comunes entre ellos. Además, se ha podido llegar a hacer un análisis gráfico de los más relevantes, evaluando sus partes, a través de una sistematización de sus escenas, evaluando sus partes, el soporte y los elementos de proyección.

\section{Palabras clave}

videomapping, arquitectura, espectáculo, perspectiva, geometría.

Composición propia sobre el videomappin El Prado, del Museo del Prado en Madrid, España 2018. Jorge Rodríguez Pascual y elaboración propia de los autores (2020), a partir de los materiales ofrecidos por materiales ofrecidos por la empresa Onionlab,

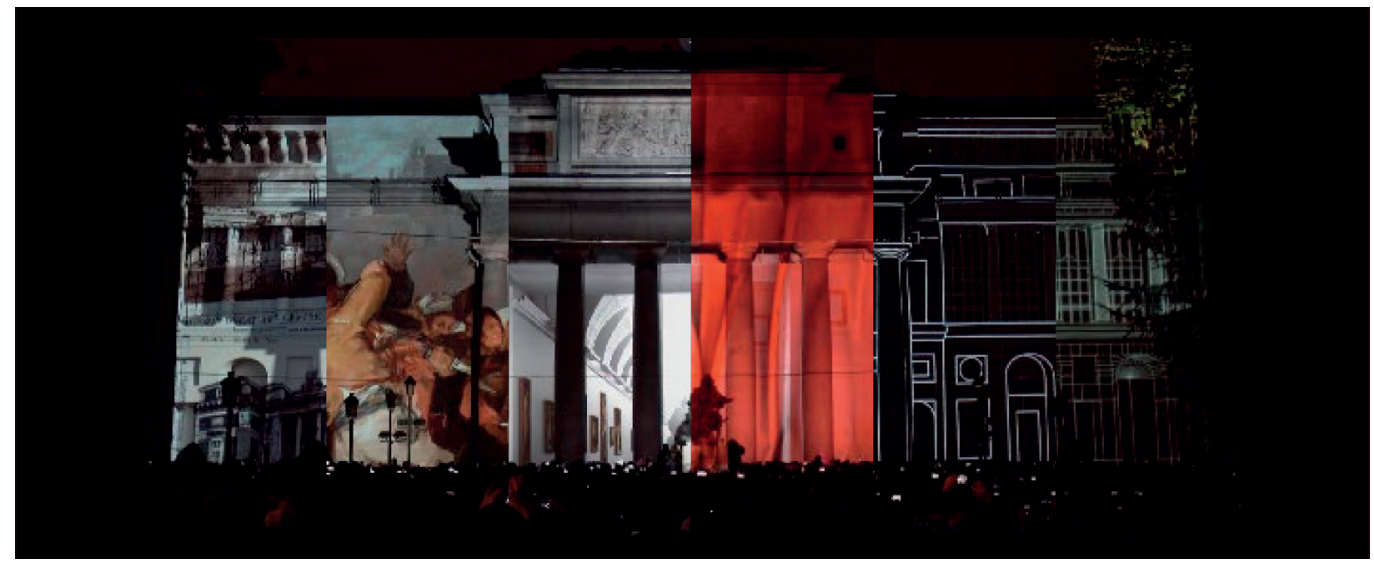




\section{A modo de introducción}

El videomapping nos enseña cómo la luz puede enriquecer el espacio público urbano. Se define como una técnica visual basada en la proyección de imágenes sobre superficies planas o volúmenes, haciendo que éstas interactúen sobre las mismas, pudiendo adquirir así un sentido narrativo y de tridimensionalidad. El contenido de vídeo que se proyecta, por tanto, está producido y adaptado para cada tipo de superficie, que va desde pequeños elementos materiales, pasando por personas o escenografías teatrales, hasta grandes espacios interiores o exteriores, adquiriendo una escala arquitectónica o incluso urbana.

La proyección así concebida permite trazar puntos tridimensionales en un plano bidimensional, añadiendo información virtual a la propia información física ya existente de la superficie sobre la que proyectar, modificando la apariencia real de los objetos gracias al control que, a través de esta técnica, se obtiene sobre su textura, forma y comportamiento. El resultado es una proyección dinámica de vídeo en tres dimensiones, generando una nueva forma en los objetos, personas o edificios a través de un cambio de su perspectiva sólida y dando así una impresión de movimiento únicamente utilizando la proyección de luz.

En la proyección tradicional se busca la generación de imágenes transparentes sobre superficies planas, sin importar cuáles sean estas; la calidad de la imagen que obtendremos variará en función de las características de esa propia superficie, pero la imagen en sí será siempre la misma. En el videomapping, por el contrario, la superficie a proyectar es conocida de antemano, y se introduce como parte indispensable del proceso de creación del proyecto, generando una animación específica para su tamaño y forma.

\section{Orígenes históricos y antecedentes}

Los seres humanos conocemos e interpretamos el mundo que nos rodea gracias a nuestros sentidos. Las sensaciones que experimentamos son captadas por los sentidos y llevadas al cerebro, que recreará la realidad y nos permitirá comprenderla.

Podríamos considerar las ilusiones ópticas como el primer antecedente del videomapping. Éstas se producen en el sentido de la vista, y su origen está en factores de orden fisiológico o cognitivo. Generan una percepción errónea de la realidad objetiva, evidenciando la gran limitación de nuestros ojos al realizar engaños de distorsión del color o la perspectiva de una escena específica.

Dentro de las ilusiones, son de especial importancia en el tema que nos ocupa el trampantojo y la anamorfosis. Ambos pretenden engañar a nuestra percepción de forma que lo representado parezca real, a través de diferentes mecanismos. La diferencia entre ambos es el punto de vista desde el cual debe observarse el truco empleado: mientras que la anamorfosis requiere de un punto específico y, generalmente, poco natural, el trampantojo trabaja con un punto de vista mucho más natural. Tanto la anamorfosis como el trampantojo, y especialmente este último, han sido utilizados en el ámbito de la arquitectura, tanto en espacios interiores como en exteriores. Sus primeras aplicaciones datan del Renacimiento, cuando se llevaron a cabo los estudios sobre la perspectiva y la proporción.

No existe una fecha exacta de origen del videomapping, si bien se estudió académicamente por primera vez a finales de la década de los 90, en la Universidad Chapel Hill de Carolina del Norte (Estados Unidos). Allí, un equipo dirigido por Ramesh Raskar trabajó en un proyecto llamado Office of the Future, con el fin de conectar oficinas de diferentes ubicaciones en una misma sala, proyectando a las personas sobre dicho espacio como si estuvieran físicamente allí.

Podemos mencionar otras experiencias recientes que nos acercan al concepto actual del videomapping:

"La mansión encantada" en DisneyLand (1969). Fue una de las primeras exhibiciones públicas en las que se proyectaron imágenes en movimiento, previamente filmadas en una película de 16 mm., sobre volúmenes fijos como bustos o cuerpos enteros, dando una sensación de animación y consiguiendo una visión fantasmagórica (fig. I). 


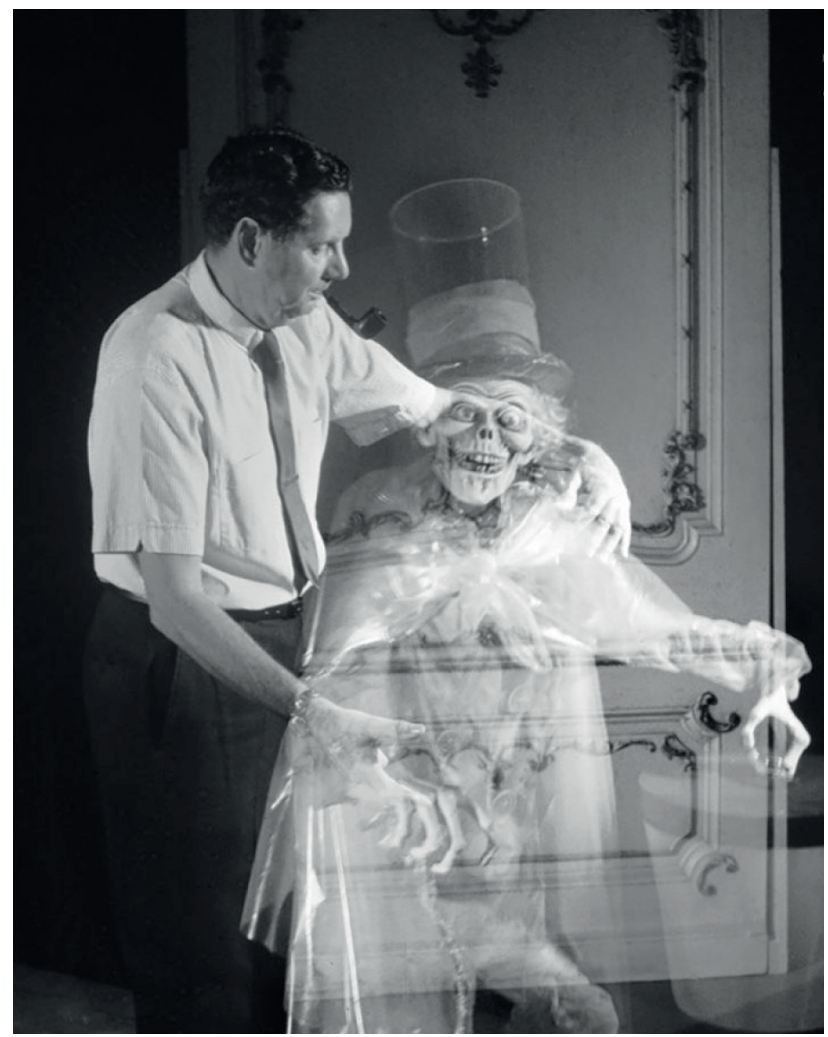

“Instalaciones", de Michael Naimark (1980). Consistía en la filmación de personas interactuando con objetos dentro de una sala, para luego proyectarlas sobre esa misma sala, dando la sensación de que estaban realmente allí, aunque con una visión un tanto onírica.

Los Festivales de "video jockey". Eran sesiones visuales en directo de creadores, que se complementaban con un set de música u otro tipo de acción; posteriormente derivaron hacia diferentes campos y, a través de la proyección de vídeos sobre diferentes superficies, creando un espectáculo audiovisual, abrieron el camino del videomapping.

"The Writting on the Wall", de Simon Attie (|99|-1993). Consistía en la proyección de fotografías de la época anterior a la guerra en las paredes de un antiguo barrio de Berlín, generando así un resultado artístico basado en instalaciones de video sobre elementos urbanos (fig. 2).

Juegos de luz y láser sobre edificios singulares. Constituyen la más importante influencia del mapping arquitectónico, y se utilizaban puntualmente, con motivo de una festividad o espectáculo concreto, o como algo más rutinario en el marco de una iluminación nocturna cambiable.

El mapping arquitectónico podría considerarse como una vertiente dentro del mapping escenográfico. Es complejo y costoso, y requiere de grandes equipos de iluminación y proyección, además de situaciones ambientales y logísticas favorables.

\section{Aspectos técnicos y proceso de creación}

La creación de un videomapping es un proceso complejo en el que intervienen muchas más variables que en una proyección tradicional. Son cuatro los elementos indispensables que forman parte del proyecto: la animación a proyectar, el proyector o grupo de proyectores, la superficie sobre la que se proyecta, y el sistema de mapeo o software. Dado el carácter artístico y subjetivo del primero, desarrollaremos ahora los otros tres. 
Fig. 2. Imagen de The Writting on the Wall, de Shimon Attie, Berlin (199|-1993). Fuente: $<$ https://gestalten.com/ blogs/journal/the-writing on-the-wall> (imagen con licencia para fines educacionales y de investigación).

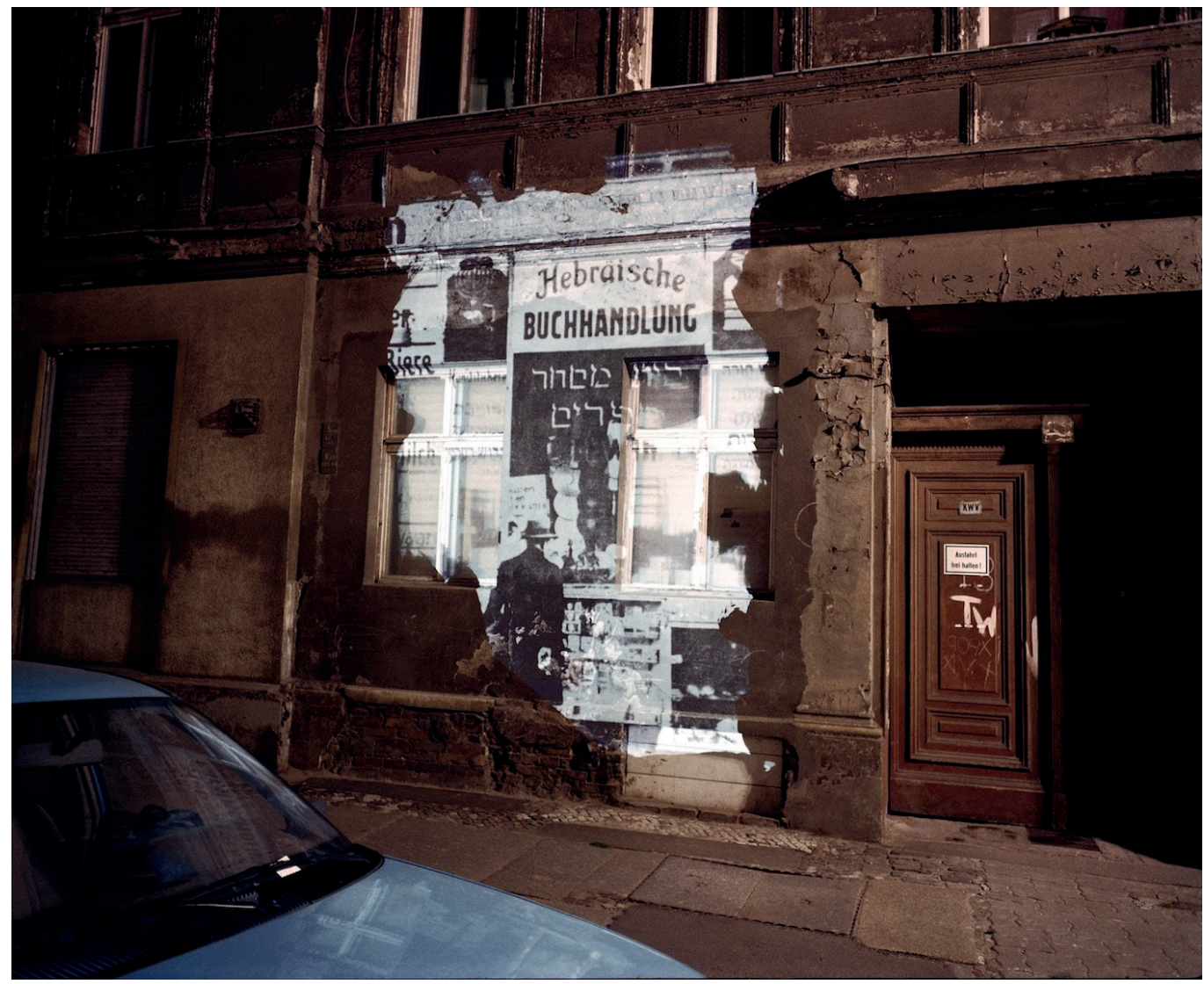

\section{El proyector}

El proyector es el dispositivo que recibe una señal de vídeo para proyectar imágenes ópticas, sean fijas o en movimiento.

En la actualidad, en el mercado existen proyectores láser y de bombilla. Una de las principales diferencias entre ambas tipologías es su vida útil, mayor en los láser, aunque en los últimos tiempos los de bombilla la están aumentando. Por otra parte, otra diferencia relevante sería la cantidad de lúmenes que pueden proporcionar en la proyección, y que en el videomapping arquitectónico debe ser muy grande; en este sentido, el rendimiento de los proyectores láser es considerablemente mayor. Una mayor cantidad de lúmenes requerirá de proyectores con una mayor potencia y, por tanto, un mayor presupuesto.

Pero si importante es la potencia lumínica del proyector, no lo son menos las características de sus lentes de proyección, cuyo ratio vendrá dado por la relación entre la distancia al objeto en el que se va a proyectar y la anchura de la imagen que se proyecta (fig. 3). También influirá en el resultado final la resolución del proyector, dado que la imagen se ampliará para cubrir una fachada completa; dado que éstas suelen ser de gran tamaño, se suele vincular dos o más dispositivos para poder obtener las dimensiones y formas deseadas (fig. 4).

\section{La superficie}

En la realización de un videomapping arquitectónico es fundamental tener toda la información posible de la fachada sobre la que se desea proyectar, trabajando generalmente con planos reales y medidas a pie de calle pero requiriendo, en ocasiones de cierta complejidad, de técnicas como la fotogrametría y el escáner láser. 
Fig. 3. Esquema explicativo de los ratios de proyección. Jorge Rodríguez Pascual y

elaboración propia de los autores (2020)

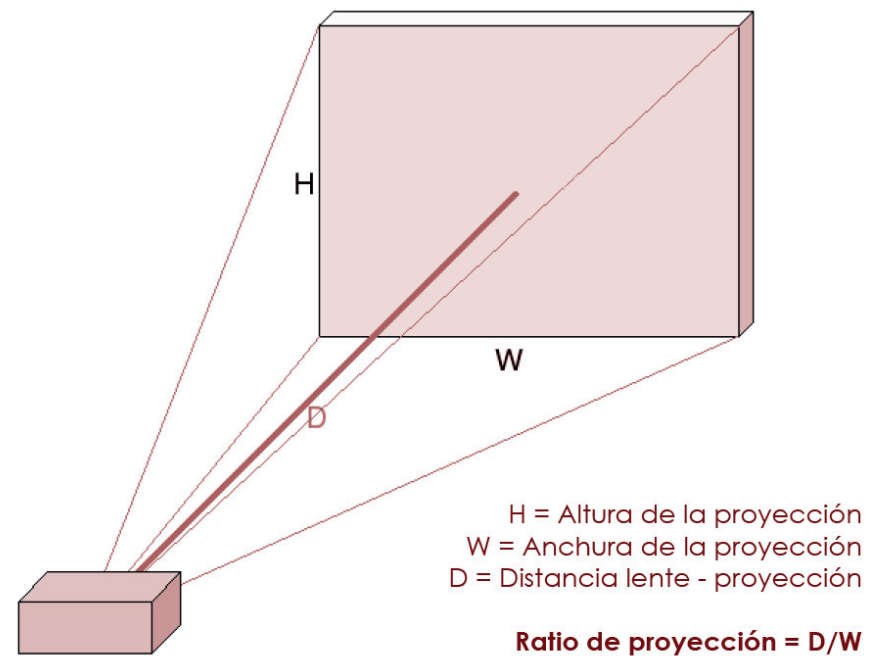

La fotogrametría, mediante la previa toma de cientos de fotografías desde diferentes ángulos alrededor de un objeto, trata de agruparlas y formar así un modelo tridimensional con el que poder trabajar, consiguiendo una definición muy precisa de las dimensiones y geometría de la fachada sobre la que proyectar. El escáner láser, por su parte, sirve para capturar la geometría y color de cualquier objeto, obteniendo una nube de puntos a través de la medición de distancias y ángulos por parte de un rayo de luz láser.

Es habitual en el videomapping que, además de definir la fachada, se proceda a la generación de un espacio virtual a escala para el posicionamiento exacto de los proyectores y fuentes de luz.

\section{El software}

Todos los software actualmente disponibles para la elaboración de un videomapping se basan en el primer teorema de Tales; mediante la razón enunciada en el mismo, permiten determinar la posición exacta de cada uno de los puntos notables del volumen sobre el que se va a proyectar.

En general, todos los programas informáticos trabajan a partir de la creación de una malla cuadriculada en la superficie sobre la que se va a proyectar, una vez haya sido modelizada. De esta manera, se logra integrar el contenido creado tridimensionalmente con el espacio físico donde se realiza la instalación.

Una vez completada la instalación, se requerirá de otro software diferente que monitorizará todo el equipo de luces y proyecciones, y trasladará la creación virtual a la realidad.

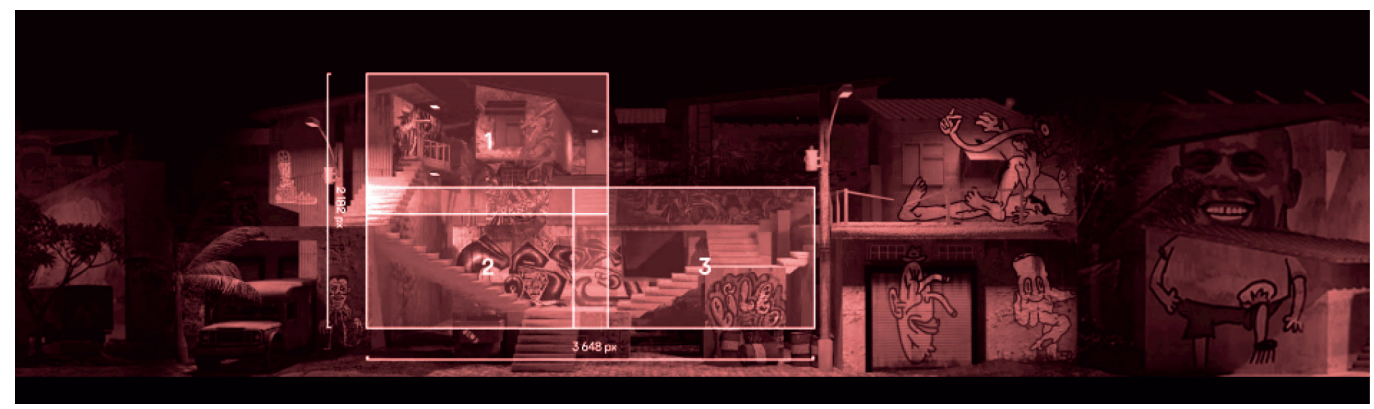

Fig. 4. Disposición de tres proyectores sobre una fachada con forma irregular. Proyecto cargo de la empresa
Lumitrix. Fuente: empresa Lumitrix (imagen de libre acceso). 
Fig. 5. Esquema explicativo de las diez tipologías principales dentro del videomapping arquitectónico. Jorge Rodriguez Pascual y de autores (2020).

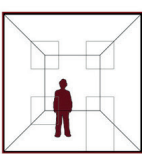

TRANSPARENCIA DELA FACHADA

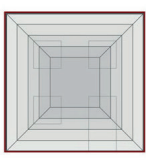
AVANCE EN
PERSPECTIVA CENTRAL

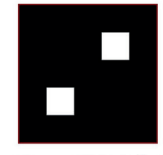

FRAGMENTACIÓN DE LA FACHADA

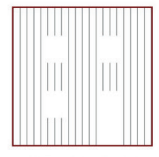

FACHADAEN

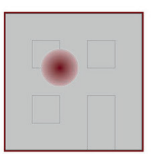

GEOMETRÍAS EN MOVIMIENTO

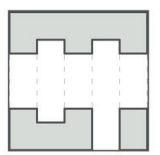

CORTE TRANSVERSAL

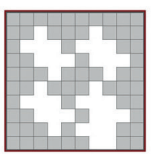

EXPLOSIÓN DE LA FACHADA

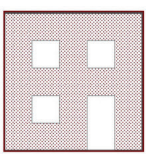

CAMBIO DE
MATERIALDAD

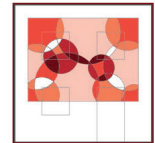

UPERPOSICIÓN DEIMÁGENES

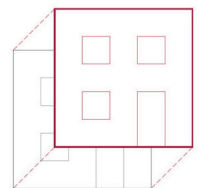

CUERPOS EMERGENTES DE LA FACHADA

\section{Las principales tipologías}

Después del estudio de las inspiraciones más recurrentes en la generación de patrones para las escenas proyectadas, se ha procedido a una clasificación tipológica dentro del videomapping arquitectónico. Para ello, se observaron decenas de proyectos diferentes, y se recogieron los rasgos comunes más característicos para una síntesis en diez categorías que recogen los aspectos más repetidos o más relevantes (fig. 5).

\begin{tabular}{|c|c|c|c|c|c|c|}
\hline ANNO & NOMBRE & LOCALIZACIÓN & MOIIVO & AUTORES & EDIFCIO & DURACIÓN \\
\hline 2011 & Helios & $\begin{array}{c}\text { Torun } \\
\text { (Polonia) }\end{array}$ & Festival "Skyway Lights" & $\begin{array}{l}\text { Limelight } \\
\text { (Hungría) }\end{array}$ & Collegium Maximum & $6^{\prime} 20^{\prime \prime}$ \\
\hline 2012 & Urban & $\begin{array}{c}\text { Kosice } \\
\text { (Eslovaquia) }\end{array}$ & Festival de la "Noche Blanca" & $\begin{array}{c}\text { OneClick } \\
\text { (Eslovaquia) }\end{array}$ & Urban Tower & $3^{3} 000^{\prime \prime}$ \\
\hline 2013 & La Féte Nationale & $\begin{array}{c}\text { Abu Dhabi } \\
\text { (Emiratos Árabes) }\end{array}$ & "43rd National Day" & $\begin{array}{r}\text { Ruggien } \\
\text { (Francia) }\end{array}$ & Burj Al Arab & $8^{\prime} 40^{\prime \prime}$ \\
\hline 2013 & Souldust & $\begin{array}{c}\text { Ozora } \\
\text { (Hungría) }\end{array}$ & Festival "OZORA" & Viktor Vicsek & Escenario Principal & $5^{\circ} 50^{\prime \prime}$ \\
\hline 2014 & À Conquista do Castelo de Óbidos & $\begin{array}{c}\text { Óbidos } \\
\text { (Portugall) }\end{array}$ & Festival "Óbidos Luz" & $\begin{array}{c}\text { Hipnose } \\
\text { (Portugal) }\end{array}$ & Castillo de Obidos & $720 "$ \\
\hline 2014 & Waterfall & $\begin{array}{c}\text { Lodz } \\
\text { (Polonia) }\end{array}$ & "Light Move Festival" & $\begin{array}{c}\text { Feel Desain } \\
\text { (Polonia) }\end{array}$ & Plac Wolnósci & $8^{\prime} 50^{\prime \prime}$ \\
\hline 2015 & Hyakki Yagyo & $\begin{array}{l}\text { Nigata } \\
\text { (Japón) }\end{array}$ & Festival Internacional "Minatopika" & $\begin{array}{c}\begin{array}{c}\text { Neba Studio } \\
\text { (Macau) }\end{array} \\
\end{array}$ & History Museum & יo" \\
\hline 2016 & Axioma & $\begin{array}{c}\text { Barcelona } \\
\text { (España) }\end{array}$ & Festival "Llum BCN" & $\begin{array}{l}\text { Onionlab } \\
\text { (España) }\end{array}$ & Palau del Lloctinent & $9^{\prime} 10^{\prime \prime}$ \\
\hline 2016 & Interconnection & $\begin{array}{r}\text { Bucarest } \\
\text { (Rumania) }\end{array}$ & Festival "iMapp" & $\begin{array}{l}\text { Limelight } \\
\text { (Hungría) }\end{array}$ & Palacio del Parlamento & $5^{\circ} 00^{\prime \prime}$ \\
\hline 2016 & Songlines & $\begin{array}{c}\text { Sydney } \\
\text { (Australia) }\end{array}$ & Concurso "Lighting the Sails" & $\begin{array}{l}\text { Rhoda Roberts } \\
\text { \& Eddy Heringson }\end{array}$ & Sydney Opera House & $15^{\prime} 50^{\prime \prime \prime}$ \\
\hline 2016 & Contrasts & $\begin{array}{l}\text { Debrecen } \\
\text { (Hungria) }\end{array}$ & "50th Flower Carnival" & $\begin{array}{c}\begin{array}{c}\text { Maxin 10sity } \\
\text { (Hungria) }\end{array} \\
\end{array}$ & Debrecen University & $3^{\prime} 10^{\prime \prime}$ \\
\hline 2017 & Cosmic Flow & $\begin{array}{c}\text { Torun } \\
\text { (Polonia) }\end{array}$ & Festival "Bella Skyway" & $\begin{array}{l}\text { Limelight } \\
\text { (Hungria) }\end{array}$ & Collegium Maximum & $5^{\prime} 30^{\prime \prime}$ \\
\hline 2017 & Beautiful Bangkok & $\begin{array}{c}\text { Bangkok } \\
\text { (Tailandia) }\end{array}$ & Festival de fin de año & $\begin{array}{c}\text { MQDC } \\
\text { (Tailandia) }\end{array}$ & Magnolias Ratchadamri & $4^{\prime} 30^{\prime \prime}$ \\
\hline 2017 & Quartz & $\begin{array}{c}\text { Shariah } \\
\text { (Emiratos Arabes) }\end{array}$ & "Shajiah Light Festival" & $\begin{array}{c}\text { Nomada } \\
\text { (Emiratos Árabes) }\end{array}$ & Al Noor Mosque & $2^{2} 30^{\prime \prime}$ \\
\hline 2018 & El Prado & $\begin{array}{l}\text { Madrid } \\
\text { (España) }\end{array}$ & Bicentenario del Museo del Prado & $\begin{array}{l}\text { Onionlab } \\
\text { (España) }\end{array}$ & Museo del Prado & $10^{\prime} 00^{\prime \prime}$ \\
\hline 2018 & What if & $\begin{array}{l}\text { Melbourne } \\
\text { (Australia) }\end{array}$ & Noche blanca de Melboume & $\begin{array}{l}\text { Limelight } \\
\text { (Hungria) }\end{array}$ & Royal Exhibition Building & $6^{\prime} 10^{\prime \prime}$ \\
\hline 2018 & La catedral de los ladrones & $\begin{array}{c}\text { Los Ángeles } \\
\text { (Estados Unidos) }\end{array}$ & Colaboración entre artistas & $\begin{array}{c}\text { Limelight } \\
\text { \& Gabriel Schama }\end{array}$ & $\begin{array}{l}\text { Escultura tallada en } \\
\text { madera }\end{array}$ & $2^{\prime} 00^{\prime \prime}$ \\
\hline 2018 & Evergreen & $\begin{array}{l}\text { Marina Bay } \\
\text { (Singapur) }\end{array}$ & Festival "ilight Marina Bay" & $\begin{array}{l}\text { Limelight } \\
\text { (Hungria) }\end{array}$ & Artscience Museum & $3^{\prime} 10^{\prime \prime}$ \\
\hline 2018 & Versus & $\begin{array}{l}\text { Slemmestad } \\
\text { (Noruega) }\end{array}$ & Festival "Factory Light" & Csaba Vilagosi & Limelight Academy & $2^{2} 30^{\prime \prime}$ \\
\hline 2018 & Diplopia & $\begin{array}{l}\text { Roma } \\
\text { (Italia) }\end{array}$ & "Solid Light Festival" & $\begin{array}{l}\text { Onionlab } \\
\text { (España) }\end{array}$ & Basilica di Santa Maria & $8^{\prime} 30^{\prime \prime}$ \\
\hline 2019 & Dual & $\begin{array}{l}\text { Moscú } \\
\text { (Rusia) }\end{array}$ & Festival "Circle of Light" & $\begin{array}{c}\text { Re:sorb } \\
\text { (Alemania) }\end{array}$ & Teatro Bolshoi & $3^{\prime} 40^{\prime \prime}$ \\
\hline 2019 & Exponent & $\begin{array}{l}\text { Moscú } \\
\text { (Rusia) }\end{array}$ & Festival "Circle of Light" & $\begin{array}{c}\text { SKGMedia } \\
\text { (China) }\end{array}$ & Museo de la Victoria & $3^{\prime} 00^{\prime \prime}$ \\
\hline 2019 & Coexistence & $\begin{array}{c}\text { Sydney } \\
\text { (Australia) }\end{array}$ & Festival "Vivid Sydney" & $\begin{array}{l}\text { Limelight } \\
\text { (Hungria) }\end{array}$ & Chatswood Arts Centre & $900 "$ \\
\hline 2019 & Another Nature & $\begin{array}{l}\text { Debrecen } \\
\text { (Hungría) }\end{array}$ & "Rescape Light Art Experience" & $\begin{array}{l}\text { Limelight } \\
\text { (Hungria) }\end{array}$ & Debrecen University & $10^{\prime} 00^{\prime \prime}$ \\
\hline 2019 & Incunabula & $\begin{array}{c}\text { Denver } \\
\text { (Estados Unidos) }\end{array}$ & Luces nocturnas en Denver & $\begin{array}{l}\text { Limelight } \\
\text { (Hungria) }\end{array}$ & Denver Clock Tower & $2^{\prime} 40^{\prime \prime}$ \\
\hline
\end{tabular}


Fig. 7. Esquema técnico de la proyección para el videomapping Evergreen, del ArtScience Museum en Marina Bay, Singapur, 2018. Jorge Rodríguez Pascual y elaboración propia de los autores (2020).
Fig. 8. Línea del tiempo analítica del videomapping El Prado, del Museo del Prado en Madrid, España, 20|8. Jorge Rodríguez Pascual y elaboración propia de los autores (2020) partir de los materiales partir de los materiales ofrecidos por la empresa Onionlab, autora del proyecto: <https://www. onionlab.com/es/work
mapping-3d/el-prado/>.
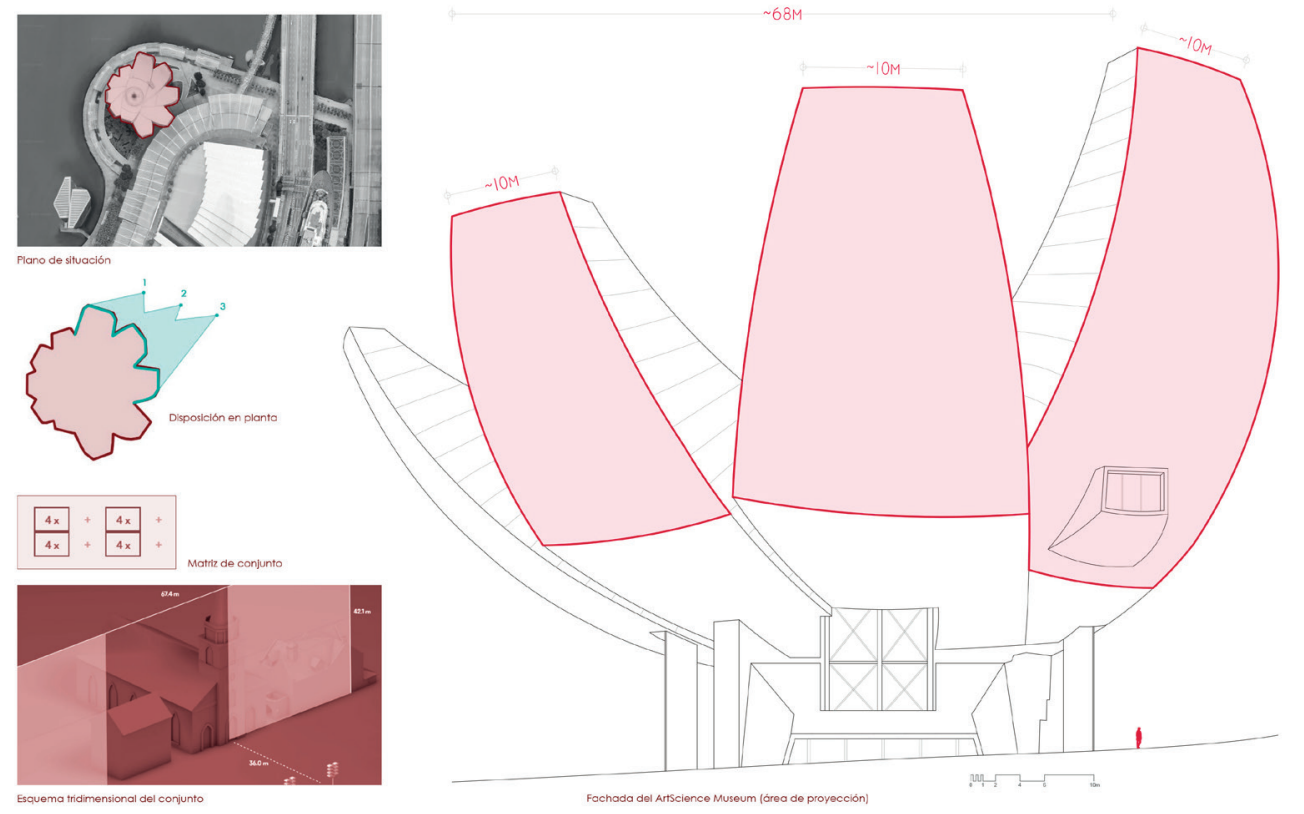

$\underset{\substack{7 \\ 2}}{\sum}$

Transparencia de la fachada. Consiste en dar la sensación de que el edificio haya perdido su fachada, permitiendo así ver su interior, que será real o imaginario; es habitual introducir un juego con la luz y la sombra, para aportar una mayor espacialidad al ambiente.

Fragmentación de la fachada. Consiste en dividir la fachada en piezas más pequeña, oscureciendo partes concretas para que otras queden a la luz y dar así la sensación de que estuvieran fragmentadas; estas escenas suelen estar asociadas a un cierto movimiento.

Geometrías en movimiento. Es la tipología que más técnicas y animaciones diferentes abarca, pues hace referencia a todas aquellas escenas en las que el papel protagonista lo desempeña una geometría ajena a la fachada original.

Explosión de la fachada. Es la tipología más usada como elemento de transición entre otras escenas, e implica la sensación de destrucción de la fachada, cuyos componentes, sean fieles o no a su materialidad original, parecen saltar por los aires.

Superposición de imágenes. Es la tipología que más se asimila a la proyección tradicional aunque, en este caso, las imágenes se componen y se animan para un espacio en concreto, recortándolas y delimitándolas.

Avance en perspectiva general. Esta tipología recoge aquellas escenas en las que la fachada pasa a ser un escenario con profundidad, visto desde una perspectiva cónica frontal, a través de la cual la cámara avanza, a modo de recorrido.

Fachada en forma analítica. Consiste en la pérdida de materialidad por parte de la fachada para convertirse en un dibujo a línea; partiendo de sus formas más representativas, se puede seguir describiendo el resto de formas que la componen o imaginar unas completamente nuevas.

Corte transversal de la fachada. En esta tipología, la fachada es seccionada transversalmente, en un corte horizontal o inclinado, dando la sensación de dividirse en dos partes, que se mantendrán estáticas o bien se irán desplazando.

Cambio de materialidad. Dentro de esta tipología se encuentran aquellas escenas en las que, gracias a la virtualidad de la proyección, la fachada cambia su material de construcción; la acción puede ser realista o, por el contrario, más utópico.

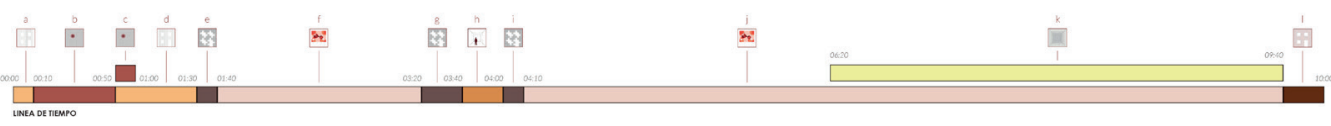




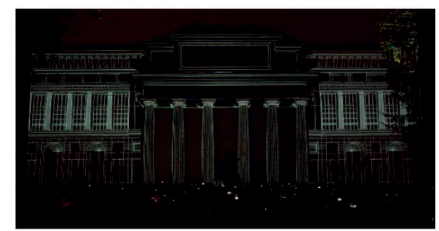

a) Fachada en forma analítica (tipo 1)

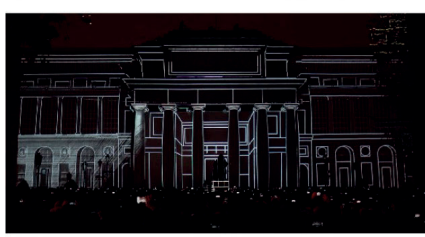

d) Fachada en forma analítica (tipo 2)

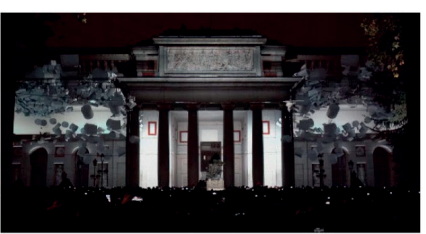

g) Explosión de la fachada (transición)

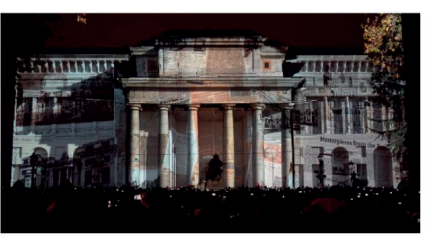

i) Superposición de imágenes (segunda etapa)

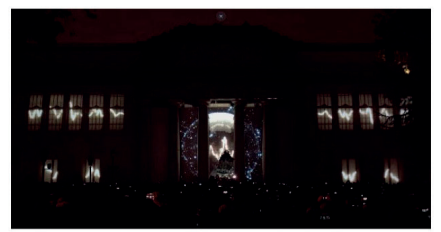

b) Geometrías en movimiento

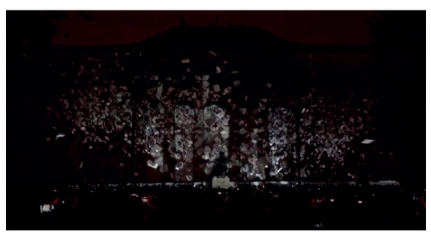

e) Explosión de la fachada (transición)

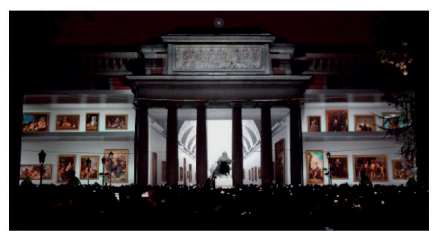

h) Transparencia de la fachada

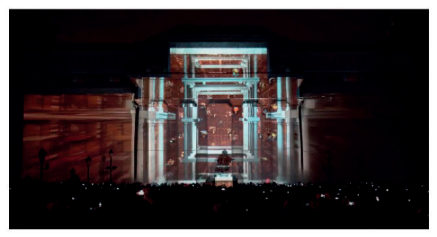

k) Avance en perspectiva frontal + Imágenes

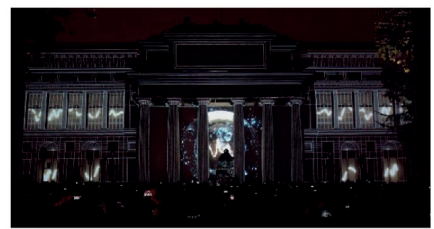

c) Analítica + Geometrías en movimiento

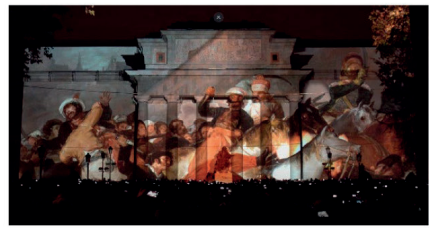

f) Superposición de imágenes (primera etapa)

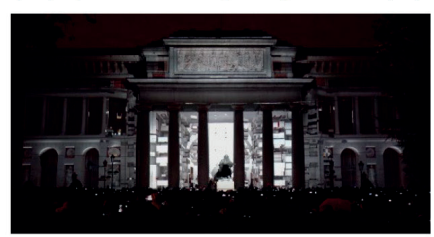

i) Explosión de la fachada (transición)

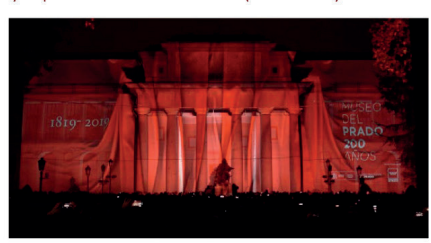

I) Cambio de materialidad (final)

Cuerpos emergentes de la fachada. En esta tipología, las escenas consiguen que una o varias partes del conjunto parezcan salirse del plano de fachada.

Gracias a esta sistematización, se ha podido analizar veinticinco proyectos relevantes de mapping arquitectónico (fig. 6), de gran variedad entre sí, con el fin de establecer su correlación con las tipologías planteadas. Además de identificar, para cada uno de ellos, datos tales como la fecha, denominación de la obra, localización y motivo del proyecto (fig. 7), autor o autores, edificios sobre el que se proyecta y duración del espectáculo, se procedió a una explicación cronológica de la obra mediante una línea del tiempo (fig. 8), con identificación de las diferentes tipologías que intervienen (fig. 9); por último, se incidió también en una plasmación de aspectos más técnicos y teóricos del videomapping.

\section{Conclusiones}

El videomapping arquitectónico está adquiriendo, paulatinamente, una mayor relevancia, por su capacidad para el enriquecimiento de los espacios urbanos e hitos arquitectónicos, especialmente aquellos que, pudiendo haber quedado en el olvido, se les revitaliza e incide en su puesta en valor. Además, desde un punto de vista más metafísico, permite dar una nueva visión de estos lugares, pasando de lo estático a lo dinámico, y llevando un paso más allá el concepto de la luz en el ámbito de la arquitectura.

A pesar de su corta historia, la creciente demanda por parte de los usuarios y el frenético avance de las nuevas tecnologías han propiciado una rápida evolución de la técnica del videomapping en los últimos años. No obstante, la información de la que, hoy en día, se dispone al respecto es muy escasa, generalmente en formato digital y a través de los sitios web de divulgadores y empresas.

La presente comunicación ha intentado hacer una primera recopilación de los datos disponibles, realizando un estudio exhaustivo de toda la información relacionada con esta técnica 
gráfica, contrastándola y finalmente presentándola a modo de un único conjunto. Así pues, partiendo de los orígenes de este arte y estableciendo sus diferencias con la proyección tradicional, se ha estudiado su realidad actual, incidiendo en los tipos de software más utilizados para crear las escenas, los fundamentos matemáticos en los que se basan, el funcionamiento de los proyectores que se utilizan y la recreación tridimensional de los modelos sobre los que se trabaja. Tras la realización de un intenso estudio de diferentes ejemplos de videomapping arquitectónico, se han conseguido establecer las tipologías más utilizadas, a partir de los patrones en las que éstas se basan. Gracias a esta sistematización, se ha podido realizar un análisis de los proyectos de videomapping más relevantes de la pasada década, recogiendo sus aspectos técnicos y artísticos fundamentales.

Por último, debemos señalar la importancia de un correcto análisis gráfico de la arquitectura de soporte, dado que sus formas influyen de manera determinante sobre la concepción y desarrollo de todo proyecto de videomapping.

\section{Referencias}

Esteves Tepedino M. A. (20 I4). El videomapping: definición, características y desarrollo. Trabajo de Fin de Grado en Publicidad y Relaciones Públicas, Dornaleteche Ruiz J., Fulgencio A. Universidad de Valladolid.

Matsuyama T. et al. (20।2). 3D Video and its applications. Berlín: Springer Publishing.

Pirenne M.H. (1970). Optics, Painting and Photography. Cambridge: Cambridge University Press.

Sánchez Ramos I. (20 I5). Trampantojo: el diseño de espacios anamórficos. Trabajo de Fin de Grado en Fundamentos de la Arquitectura, Álvaro Tordesillas A., Alonso Rodríguez M. Universidad de Valladolid.

Sánchez Salinas D. (2019). Matte Painting: La geometría oculta del cine. Trabajo de Fin de Grado en Fundamentos de la Arquitectura, López Bragado D. Universidad de Valladolid.

\footnotetext{
Autores

Víctor-Antonio Lafuente Sánchez, Universidad de Valladolid, victorantonio.lafuente@uva.es
} Daniel López Bragado, Universidad de Valladolid, daniel.lopez.bragado@uva.es

Para citar este artículo: Lafuente Sánchez Víctor-Antonio, López Bragado Daniel (2021).Videomapping arquitectónico: la tecnología al servicio de la renovación del espacio/Architectural Videomapping:Technology at the Service of Space Renovation. In Arena A., Arena M., Mediati D., Raffa P. (a cura di). Connettere. Un disegno per annodare e tessere. Linguaggi Distanze Tecnologie. Atti del $42^{\circ}$ Convegno Internazionale dei Docenti delle Discipline della Rappresentazione/Connecting. Drawing for weaving relationship. Languages Distances Technologies. Proceedings of the 42th International Conference of Representation Disciplines Teachers. Milano: FrancoAngeli, pp. 2403-2420. 


\title{
Architectural Videomapping: Technology at the Service of Space Renovation
}

\author{
Víctor-Antonio Lafuente Sánchez \\ Daniel López Bragado
}

Abstract

Architectural videomapping is an alternative to the regular perception of urban spaces, introducing the variable of movement in the static. This increasingly popular technique takes the concept of light further in the context of architecture, to a level where forms are defined, modified or altered by operations of movement in a global process that also includes sound effects.

This contribution aims to investigate the devices and techniques used to carry out this new form of representation and graphic intervention, analyzing a large number of different projects, and looking for the common elements between them. In addition, it has been possible to make a graphic analysis of the most relevant, evaluating their parts, through a systematization of their scenes, evaluating their parts, the support and the projection elements

Keywords

videomapping, architecture, show, perspective, geometry.

Own composition on the videomapping El Prado, from the Prado Museum in Madrid, Spain, 2018. Jorge Rodríguez Pascual and own elaboration of the authors (2020) from the materials offered by the oni the Onionlab company.

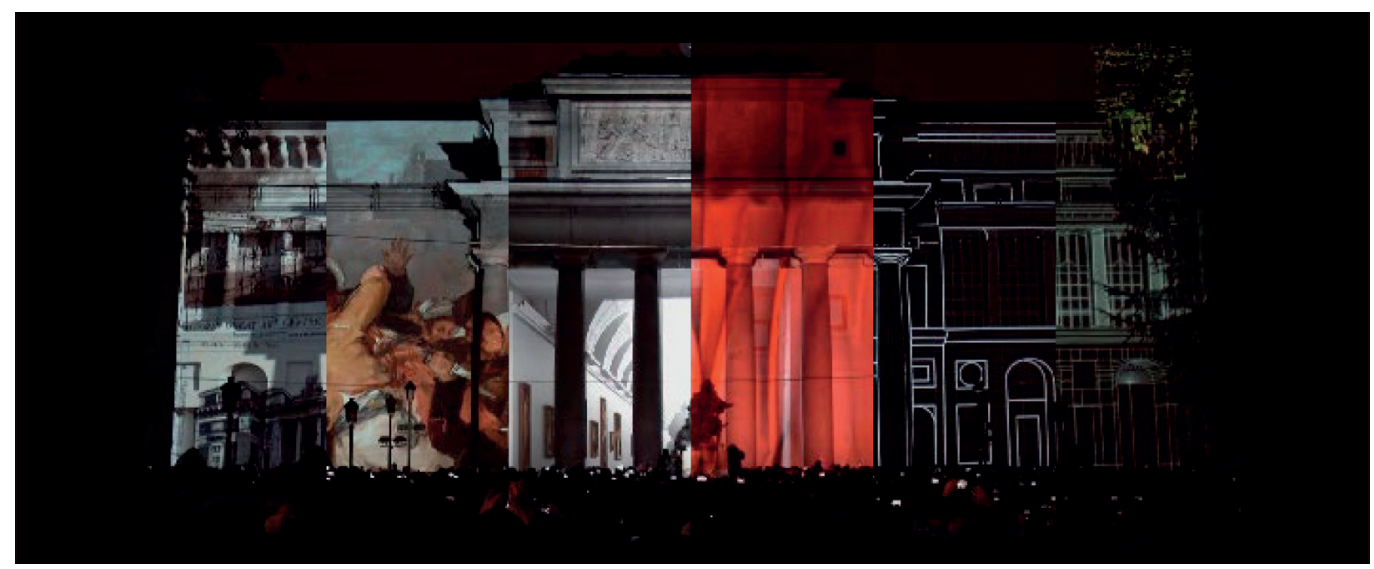




\section{By way of introduction}

Video mapping teaches us how light can enrich urban public space. It is defined as a visual technique based on the projection of images on flat surfaces or volumes, making them interact on them, thus being able to acquire a narrative and three-dimensional sense. The video content that is projected, therefore, is produced and adapted for each type of surface, ranging from small material elements, through people or theatrical scenography, to large interior or exterior spaces, acquiring an architectural or even urban scale.

The projection thus conceived allows three-dimensional points to be traced on a two-dimensional plane, adding virtual information to the physical information already existing on the surface on which to project, modifying the real appearance of the objects thanks to the control that, through this technique, is got about its texture, shape and behavior. The result is a dynamic projection of video in three dimensions, generating a new shape in objects, people or buildings through a change in their solid perspective and thus giving an impression of movement only using the projection of light.

In traditional projection, the generation of transparent images on flat surfaces is sought, no matter what they are; the quality of the image that we will obtain will vary depending on the characteristics of that surface, but the image itself will always be the same. In videomapping, on the contrary, the surface to be projected is known in advance, and it is introduced as an indispensable part of the project creation process, generating a specific animation for its size and shape.

\section{Historical origins and antecedents}

Human beings know and interpret the world around us thanks to our senses. The sensations we experience are captured by the senses and brought to the brain, which will recreate reality and allow us to understand it.

We could consider optical illusions as the first antecedent of videomapping. They occur in the sense of sight, and their origin is in physiological or cognitive factors. They generate an erroneous perception of objective reality, evidencing the great limitation of our eyes when performing tricks of distortion of the color or the perspective of a specific scene.

Among illusions, trompe l'oeil and anamorphosis are of special importance in the subject at hand. Both intend to deceive our perception so that what is represented seems real, through different mechanisms. The difference between the two is the point of view from which the trick used should be observed: while anamorphosis requires a specific point and is generally unnatural, trompe l'oeil works from a much more natural point of view. Both anamorphosis and trompe l'oeil, and especially the latter, have been used in the field of architecture, both indoors and outdoors. Their first applications date from the Renaissance, when studies on perspective and proportion were carried out.

There is no exact date of origin for videomapping, although it was studied academically for the first time in the late 1990s, at Chapel Hill University in North Carolina (United States). There, a team led by Ramesh Raskar worked on a project called Office of the Future, in order to connect offices from different locations in the same room, projecting people onto that space as if they were physically there.

We can mention other recent experiences that bring us closer to the current concept of videomapping:

"The haunted mansion" in DisneyLand (1969). It was one of the first public exhibitions in which moving images, previously filmed on $16 \mathrm{~mm}$ film, were projected on fixed volumes such as busts or whole bodies, giving a sense of animation and achieving a ghostly vision. "Installations", by Michael Naimark (1980). It consisted of filming people interacting with objects within a room, and then projecting them onto that same room, giving the feeling that they were really there, although with a somewhat dreamlike vision.

The "video jockey" festivals. They were live visual sessions of creators, which were complemented by a set of music or another type of action; later they drifted to different fields and, 


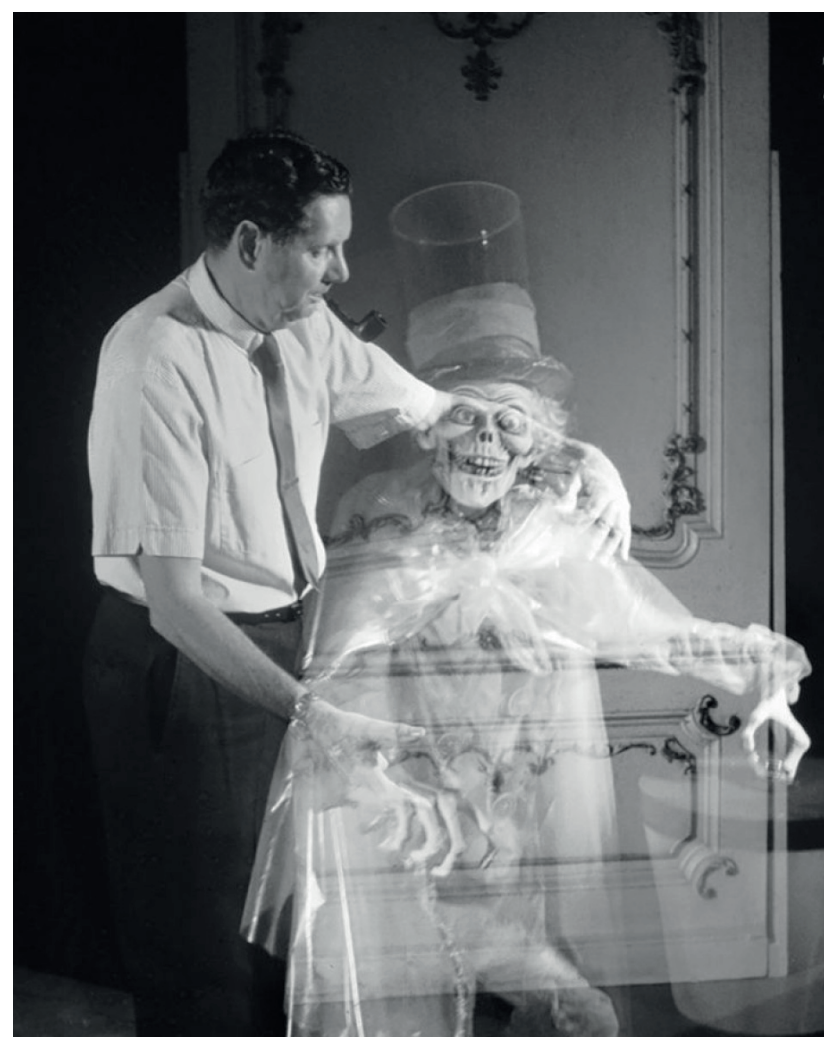

through the projection of videos on different surfaces, creating an audiovisual show, they opened the way of videomapping.

"The Writting on the Wall", by Simon Attie (199|-1993). It consisted of the projection of photographs from the pre-war era on the walls of an old Berlin neighborhood, thus generating an artistic result based on video installations on urban elements.

Games of light and laser on singular buildings. They constitute the most important influence of architectural mapping, and were used occasionally, on the occasion of a specific festival or show, or as something more routine within the framework of changeable night lighting. The architectural mapping could be considered as a slope within the scenographic mapping. It is complex and expensive, and requires large lighting and projection equipment, as well as favorable environmental and logistical situations.

\section{Technical aspects and creation process}

Creating a videomapping is a complex process involving many more variables than a traditional projection. There are four essential elements that are part of the project: the animation to be projected, the projector or group of projectors, the surface on which it is projected, and the mapping system or software. Given the artistic and subjective nature of the first one, we will now develop the other three elements.

\section{The projector}

The projector is the device that receives a video signal to project optical images, whether still or moving.

Today there are laser and bulb projectors on the market. One of the main differences between the two types is their useful life, which is longer in lasers, although in recent times 
Fig. 2. Image from The Writting on the Wall, by Shimon Attie, Berlin (1991-1993). Source: $<$ https://gestalten.com/ blogs/journal/the-writing on-the-wall> (image licensed for educationa and research purposes)

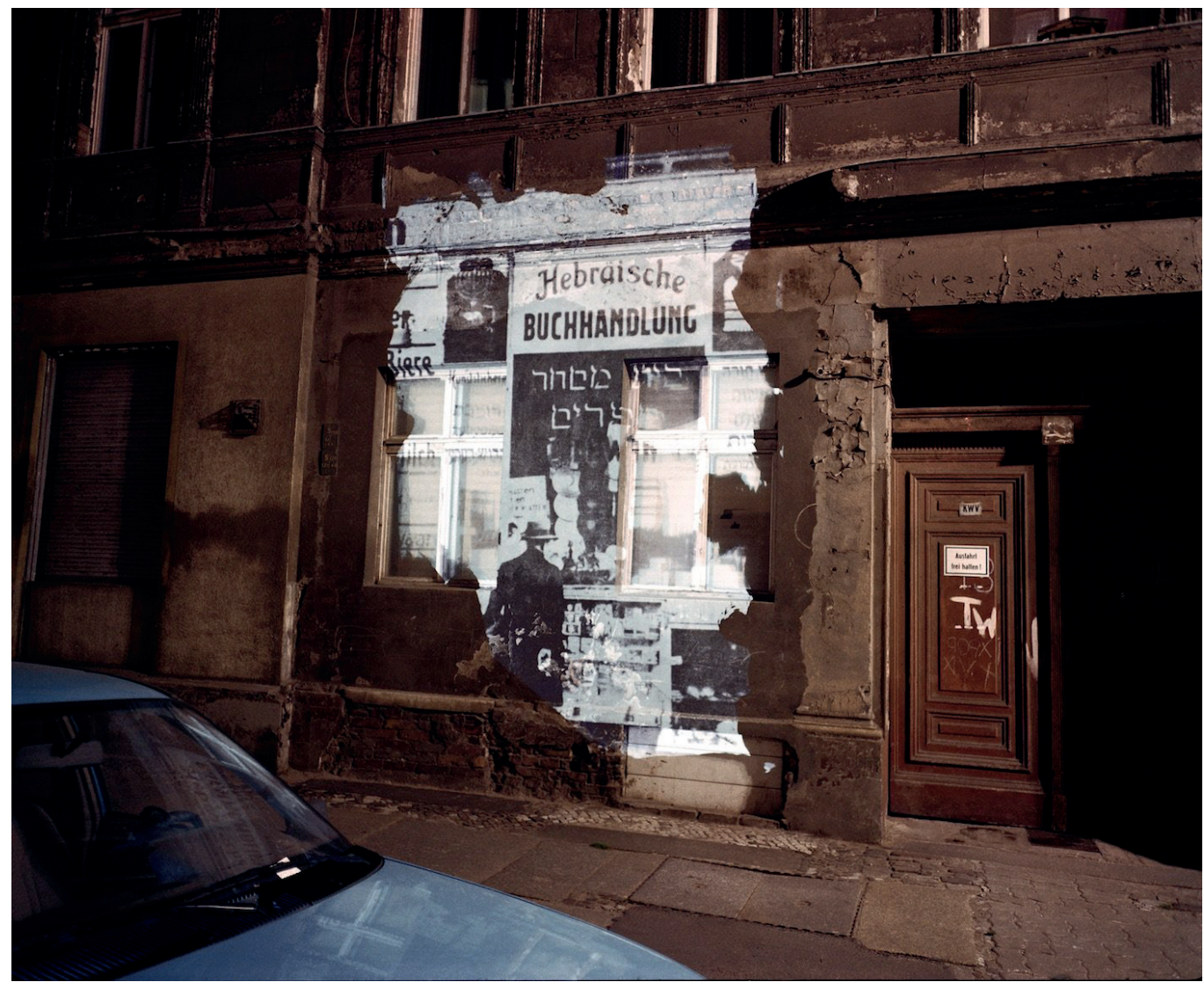

those of lightbulbs are increasing it. On the other hand, another relevant difference would be the amount of lumens that they can provide in the projection, and that in architectural videomapping must be very large; in this sense, the performance of laser projectors is considerably higher. A higher amount of lumens will require projectors with a higher power and, therefore, a higher budget.

But if the projector's light power is important, the characteristics of its projection lenses are no less important, whose ratio will be given by the relation between the distance to the object on which it is going to be projected and the width of the image that is projected. The resolution of the projector will also influence the final result, since the image will be enlarged to cover a complete facade; since these are usually large, two or more devices are usually linked to obtain the desired dimensions and shapes.

\section{The surface}

In carrying out an architectural videomapping, it is essential to have all the possible information about the façade on which you want to project, generally working with real plans and measurements at street level but requiring, on occasions of certain complexity, techniques such as photogrammetry and the laser scanner.

Photogrammetry, by previously taking hundreds of photographs from different angles around an object, tries to group them and thus form a three-dimensional model with which to work, achieving a very precise definition of the dimensions and geometry of the façade on which to project. The laser scanner, for its part, is used to capture the geometry and color of any object, obtaining a cloud of points through the measurement of distances and angles by a beam of laser light.

It is common in videomapping that, in addition to defining the façade, a virtual space is generated to scale for the exact positioning of the projectors and light sources. 
Fig. 3. Explanatory diagram of the projection ratios. Jorge Rodríguez Pascual and the authors own elaboration (2020)

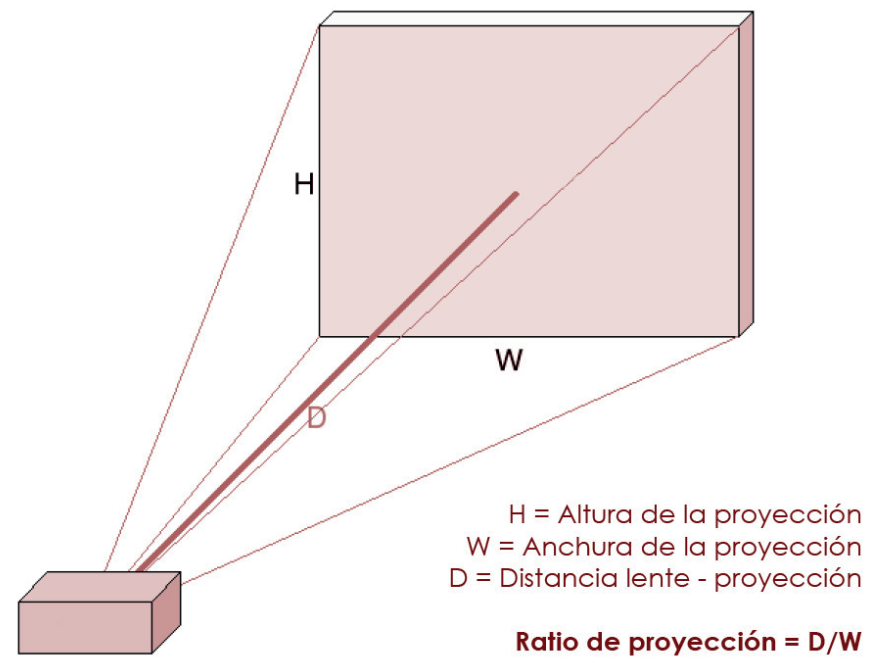

The software

All currently available software for videomapping is based on Thales' first theorem; By means of the reason stated in it, they allow to determine the exact position of each one of the notable points of the volume on which the projection is going to be made.

In general, all computer programs work from the creation of a grid mesh on the surface on which the projection is going to be made, once it has been modeled. In this way, it is possible to integrate the content created three-dimensionally with the physical space where the installation takes place.

Once the installation is completed, a different software will be required that will monitor all the lighting and projection equipment, and will transfer the virtual creation to reality.

\section{The main typologies}

After studying the most recurrent inspirations in the generation of patterns for the projected scenes, a typological classification has been carried out within the architectural videomapping. For this, dozens of different projects were observed, and the most characteristic common features were collected for a synthesis in ten categories that collect the most repeated or most relevant aspects.

Transparency of the facade. It consists of giving the feeling that the building has lost its facade, thus allowing you to see its interior, which will be real or imaginary; it is common to introduce a game with light and shadow, to provide greater space to the environment.

Fragmentation of the facade. It consists of dividing the façade into smaller pieces, darkening specific parts so that others remain in the light and thus give the feeling that they were fragmented; these scenes are usually associated with a certain movement.

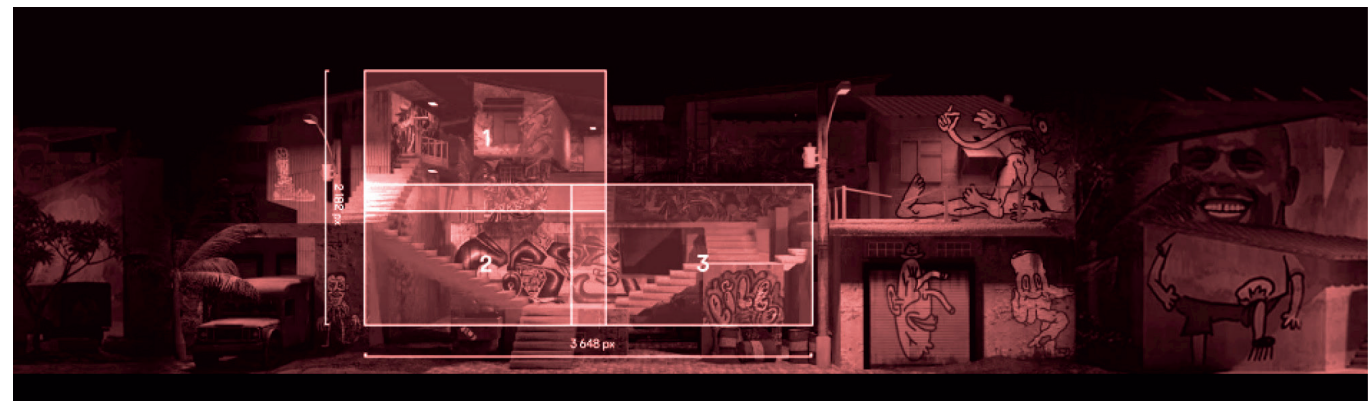


Fig. 5. Explanatory diagram of the ten main typologies within the architectural videomapping. Jorge Rodríguez Pascual and the authors' own elaboration (2020).

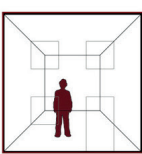

TRANSPARENCIA DELA FACHADA

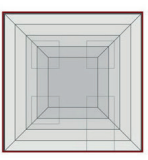
AVANCE EN
PERSPECTIVA CENTRAL

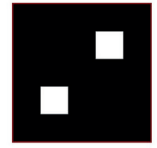

FRAGMENTACIÓN DE LA FACHADA

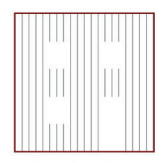

FACHADAEN

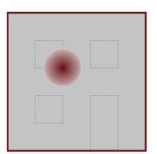

GEOMETRÍAS EN MOVIMIENTO

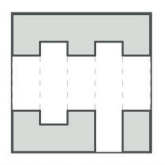

CORTE TRANSVERSAL

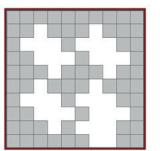

EXPLOSIÓN DE LA FACHADA

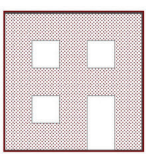

CAMBIO DE

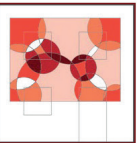

SUPERPOSICIÓN DE IMÁGENES

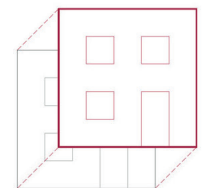

CUERPOS EMERGENTES DE LA FACHADA

Geometries in motion. It is the typology that covers the most different techniques and animations, since it refers to all those scenes in which the main role is played by a geometry alien to the original façade.

Explosion of the facade. It is the most used typology as a transition element between other scenes, and implies the sensation of destruction of the façade, whose components, whether or not they are faithful to their original materiality, seem to be blown up.

\begin{tabular}{|c|c|c|c|c|c|c|}
\hline ANNO & NOMBRE & LOCALIZACIÓN & MOIIVO & AUTORES & EDIFCIO & DURACIÓN \\
\hline 2011 & Helios & $\begin{array}{c}\text { Torun } \\
\text { (Polonia) }\end{array}$ & Festival "Skyway Lights" & $\begin{array}{l}\text { Limelight } \\
\text { (Hungría) }\end{array}$ & Collegium Maximum & $6^{\prime} 20^{\prime \prime}$ \\
\hline 2012 & Urban & $\begin{array}{c}\text { Kosice } \\
\text { (Eslovaquia) }\end{array}$ & Festival de la "Noche Blanca" & $\begin{array}{c}\text { OneClick } \\
\text { (Eslovaquia) }\end{array}$ & Urban Tower & $3^{3} 000^{\prime \prime}$ \\
\hline 2013 & La Féte Nationale & $\begin{array}{c}\text { Abu Dhabi } \\
\text { (Emiratos Árabes) }\end{array}$ & "43rd National Day" & $\begin{array}{r}\text { Ruggien } \\
\text { (Francia) }\end{array}$ & Burj Al Arab & $8^{\prime} 40^{\prime \prime}$ \\
\hline 2013 & Souldust & $\begin{array}{c}\text { Ozora } \\
\text { (Hungría) }\end{array}$ & Festival "OZORA" & Viktor Vicsek & Escenario Principal & $5^{\circ} 50^{\prime \prime}$ \\
\hline 2014 & À Conquista do Castelo de Óbidos & $\begin{array}{c}\text { Óbidos } \\
\text { (Portugall) }\end{array}$ & Festival "Óbidos Luz" & $\begin{array}{c}\text { Hipnose } \\
\text { (Portugal) }\end{array}$ & Castillo de Obidos & $720 "$ \\
\hline 2014 & Waterfall & $\begin{array}{c}\text { Lodz } \\
\text { (Polonia) }\end{array}$ & "Light Move Festival" & $\begin{array}{c}\text { Feel Desain } \\
\text { (Polonia) }\end{array}$ & Plac Wolnósci & $8^{\prime} 50^{\prime \prime}$ \\
\hline 2015 & Hyakki Yagyo & $\begin{array}{l}\text { Nigata } \\
\text { (Japón) }\end{array}$ & Festival Internacional "Minatopika" & $\begin{array}{c}\begin{array}{c}\text { Neba Studio } \\
\text { (Macau) }\end{array} \\
\end{array}$ & History Museum & יo" \\
\hline 2016 & Axioma & $\begin{array}{c}\text { Barcelona } \\
\text { (España) }\end{array}$ & Festival "Llum BCN" & $\begin{array}{l}\text { Onionlab } \\
\text { (España) }\end{array}$ & Palau del Lloctinent & $9^{\prime} 10^{\prime \prime}$ \\
\hline 2016 & Interconnection & $\begin{array}{r}\text { Bucarest } \\
\text { (Rumania) }\end{array}$ & Festival "iMapp" & $\begin{array}{l}\text { Limelight } \\
\text { (Hungría) }\end{array}$ & Palacio del Parlamento & $5^{\circ} 00^{\prime \prime}$ \\
\hline 2016 & Songlines & $\begin{array}{c}\text { Sydney } \\
\text { (Australia) }\end{array}$ & Concurso "Lighting the Sails" & $\begin{array}{l}\text { Rhoda Roberts } \\
\text { \& Eddy Heringson }\end{array}$ & Sydney Opera House & $15^{\prime} 50^{\prime \prime \prime}$ \\
\hline 2016 & Contrasts & $\begin{array}{l}\text { Debrecen } \\
\text { (Hungria) }\end{array}$ & "50th Flower Carnival" & $\begin{array}{c}\begin{array}{c}\text { Maxin 10sity } \\
\text { (Hungria) }\end{array} \\
\end{array}$ & Debrecen University & $3^{\prime} 10^{\prime \prime}$ \\
\hline 2017 & Cosmic Flow & $\begin{array}{c}\text { Torun } \\
\text { (Polonia) }\end{array}$ & Festival "Bella Skyway" & $\begin{array}{l}\text { Limelight } \\
\text { (Hungria) }\end{array}$ & Collegium Maximum & $5^{\prime} 30^{\prime \prime}$ \\
\hline 2017 & Beautiful Bangkok & $\begin{array}{c}\text { Bangkok } \\
\text { (Tailandia) }\end{array}$ & Festival de fin de año & $\begin{array}{c}\text { MQDC } \\
\text { (Tailandia) }\end{array}$ & Magnolias Ratchadamri & $4^{\prime} 30^{\prime \prime}$ \\
\hline 2017 & Quartz & $\begin{array}{c}\text { Shariah } \\
\text { (Emiratos Arabes) }\end{array}$ & "Shajiah Light Festival" & $\begin{array}{c}\text { Nomada } \\
\text { (Emiratos Árabes) }\end{array}$ & Al Noor Mosque & $2^{2} 30^{\prime \prime}$ \\
\hline 2018 & El Prado & $\begin{array}{l}\text { Madrid } \\
\text { (España) }\end{array}$ & Bicentenario del Museo del Prado & $\begin{array}{l}\text { Onionlab } \\
\text { (España) }\end{array}$ & Museo del Prado & $10^{\prime} 00^{\prime \prime}$ \\
\hline 2018 & What if & $\begin{array}{l}\text { Melbourne } \\
\text { (Australia) }\end{array}$ & Noche blanca de Melboume & $\begin{array}{l}\text { Limelight } \\
\text { (Hungria) }\end{array}$ & Royal Exhibition Building & $6^{\prime} 10^{\prime \prime}$ \\
\hline 2018 & La catedral de los ladrones & $\begin{array}{c}\text { Los Ángeles } \\
\text { (Estados Unidos) }\end{array}$ & Colaboración entre artistas & $\begin{array}{c}\text { Limelight } \\
\text { \& Gabriel Schama }\end{array}$ & $\begin{array}{l}\text { Escultura tallada en } \\
\text { madera }\end{array}$ & $2^{\prime} 00^{\prime \prime}$ \\
\hline 2018 & Evergreen & $\begin{array}{l}\text { Marina Bay } \\
\text { (Singapur) }\end{array}$ & Festival "ilight Marina Bay" & $\begin{array}{l}\text { Limelight } \\
\text { (Hungria) }\end{array}$ & Artscience Museum & $3^{\prime} 10^{\prime \prime}$ \\
\hline 2018 & Versus & $\begin{array}{l}\text { Slemmestad } \\
\text { (Noruega) }\end{array}$ & Festival "Factory Light" & Csaba Vilagosi & Limelight Academy & $2^{2} 30^{\prime \prime}$ \\
\hline 2018 & Diplopia & $\begin{array}{l}\text { Roma } \\
\text { (Italia) }\end{array}$ & "Solid Light Festival" & $\begin{array}{l}\text { Onionlab } \\
\text { (España) }\end{array}$ & Basilica di Santa Maria & $8^{\prime} 30^{\prime \prime}$ \\
\hline 2019 & Dual & $\begin{array}{l}\text { Moscú } \\
\text { (Rusia) }\end{array}$ & Festival "Circle of Light" & $\begin{array}{c}\text { Re:sorb } \\
\text { (Alemania) }\end{array}$ & Teatro Bolshoi & $3^{\prime} 40^{\prime \prime}$ \\
\hline 2019 & Exponent & $\begin{array}{l}\text { Moscú } \\
\text { (Rusia) }\end{array}$ & Festival "Circle of Light" & $\begin{array}{c}\text { SKGMedia } \\
\text { (China) }\end{array}$ & Museo de la Victoria & $3^{\prime} 00^{\prime \prime}$ \\
\hline 2019 & Coexistence & $\begin{array}{c}\text { Sydney } \\
\text { (Australia) }\end{array}$ & Festival "Vivid Sydney" & $\begin{array}{l}\text { Limelight } \\
\text { (Hungria) }\end{array}$ & Chatswood Arts Centre & $900 "$ \\
\hline 2019 & Another Nature & $\begin{array}{l}\text { Debrecen } \\
\text { (Hungría) }\end{array}$ & "Rescape Light Art Experience" & $\begin{array}{l}\text { Limelight } \\
\text { (Hungria) }\end{array}$ & Debrecen University & $10^{\prime} 00^{\prime \prime}$ \\
\hline 2019 & Incunabula & $\begin{array}{c}\text { Denver } \\
\text { (Estados Unidos) }\end{array}$ & Luces nocturnas en Denver & $\begin{array}{l}\text { Limelight } \\
\text { (Hungria) }\end{array}$ & Denver Clock Tower & $2^{\prime} 40^{\prime \prime}$ \\
\hline
\end{tabular}


Fig. 7. Technical scheme of the projection for the Evergreen videomapping of the ArtScience Museum in Marina Bay, Singapore, 2018 Jorge Rodríguez Pascual and the authors own elaboration (2020).
Fig. 8. Analytical timeline of the videomapping El Prado, from the Prado Museum in Madrid, Spain, 20 I. Jorge Rodríguez Pascual and the authors own elaboration (2020) based on the marias based on the materials offered by the Onionlab company, author of the project: < https.//www. mapping-3d/el-prado/>.
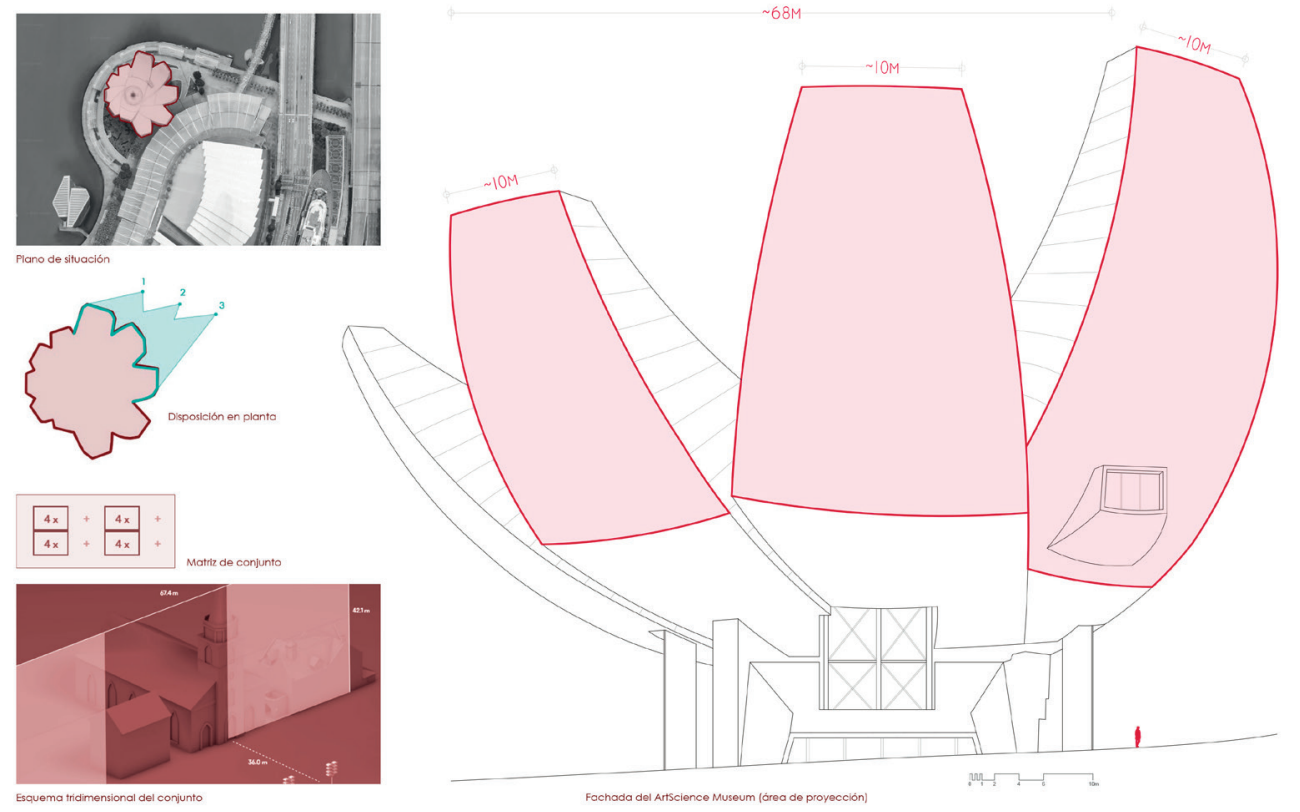

$\sum_{\substack{4 \\ \frac{1}{2}}}$

Image overlay. It is the typology that most assimilates the traditional projection, although, in this case, the images are composed and animated for a specific space, cutting and delimiting them.

Progress in general perspective. This typology includes those scenes in which the façade becomes a scene with depth, seen from a frontal conical perspective, through which the camera moves forward, as a route.

Facade in analytical form. It consists of the loss of materiality by the facade to become a line drawing; starting from its most representative forms, it is possible to continue describing the rest of the forms that compose it or imagine completely new ones.

Cross section of the facade. In this typology, the façade is cross-sectioned, in a horizontal or inclined cut, giving the feeling of dividing into two parts, which will remain static or will move. Change in materiality. Within this typology are those scenes in which, thanks to the virtuality of the projection, the façade changes its construction material; the action can be realistic or, conversely, more utopian.

Emerging bodies of the facade. In this typology, the scenes make one or more parts of the ensemble appear to go beyond the façade plane.

Thanks to this systematization, it has been possible to analyse twenty-five relevant architectural mapping projects, of great variety among themselves, in order to establish their correlation with the proposed typologies. In addition to identifying, for each one of them, data such as the date, name of the work, location and reason for the project, author or authors, buildings on which it is projected and duration of the show, we proceeded to a chronological explanation of the work through a time line, identifying the different typologies involved; lastly, there was also an impact on a representation of more technical and theoretical aspects of videomapping.

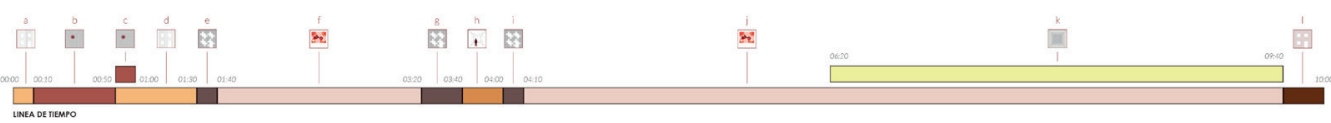




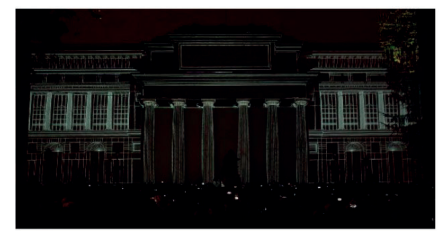

a) Fachada en forma analítica (tipo 1)

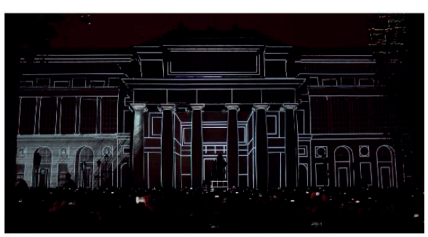

d) Fachada en forma analítica (tipo 2)

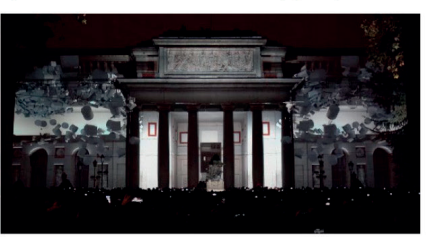

g) Explosión de la fachada (transición)

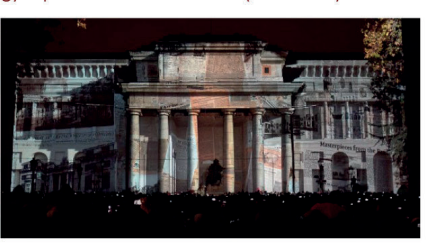

i) Superposición de imágenes (segunda etapa)

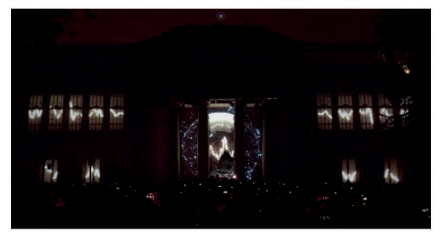

b) Geometrías en movimiento

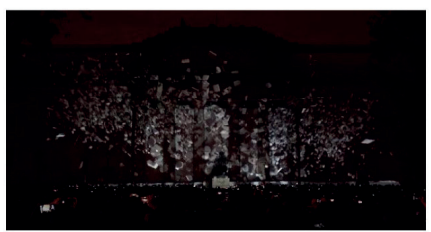

e) Explosión de la fachada (transición)

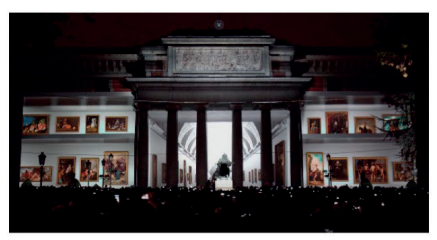

h) Transparencia de la fachada

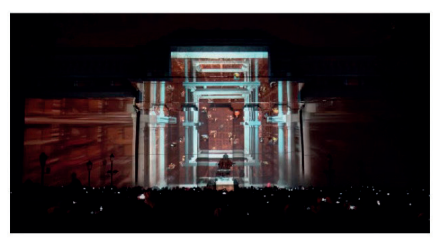

k) Avance en perspectiva frontal + Imágenes

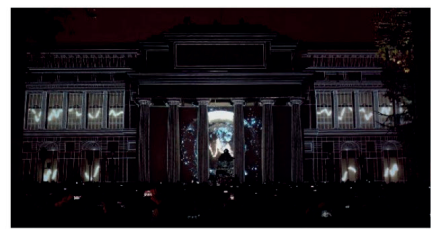

c) Analítica + Geometrías en movimiento

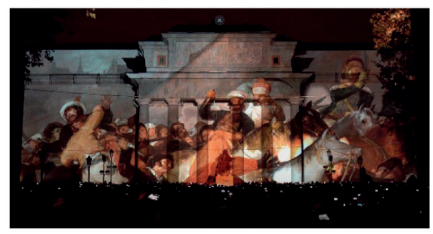

f) Superposición de imágenes (primera etapa)

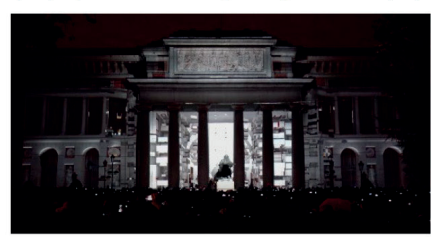

i) Explosión de la fachada (transición)

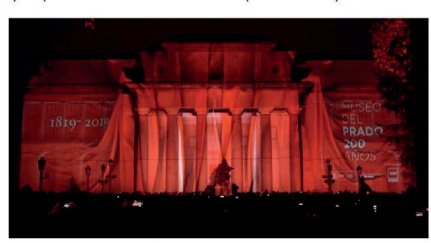

1) Cambio de materialidad (final)

\section{Conclusions}

Architectural videomapping is gradually acquiring greater relevance, due to its ability to enrich urban spaces and architectural landmarks, specially those that, although they may have been forgotten, are revitalized and have an impact on their enhancement. Furthermore, from a more metaphysical point of view, it allows us to give a new vision of these places, going from the static to the dynamic, and taking the concept of light one step further in the field of architecture.

Despite its short history, the growing demand from users and the frenzied advance of new technologies have led to a rapid evolution of the videomapping technique in recent years. However, the information currently available in this regard is very scarce, generally in digital format and through the websites of disseminators and companies.

This communication has tried to make a first compilation of the available data, carrying out an exhaustive study of all the information related to this graphic technique, contrasting it and finally presenting it as a single set. Thus, starting from the origins of this art and establishing its differences with traditional projection, its current reality has been studied, focusing on the types of software most used to create the scenes, the mathematical foundations on which they are based, the operation of the projectors that are used and the three-dimensional recreation of the models on which one works.

After carrying out an intense study of different examples of architectural videomapping, the most commonly used typologies have been established, based on the patterns on which they are based. Thanks to this systematization, it has been possible to carry out an analysis of the most relevant videomapping projects of the past decade, collecting their fundamental technical and artistic aspects.

Finally, we must point out the importance of a correct graphic analysis of the support architecture, since its forms have a decisive influence on the conception and development of any videomapping project. 


\section{References}

Esteves Tepedino M. A. (20|4). El videomapping: definición, características y desarrollo. Trabajo de Fin de Grado en Publicidad y Relaciones Públicas, Dornaleteche Ruiz J., Fulgencio A. Universidad de Valladolid.

Matsuyama T. et al. (20/2). 3D Video and its applications. Berlín: Springer Publishing.

Pirenne M.H. (1970). Optics, Painting and Photography. Cambridge: Cambridge University Press.

Sánchez Ramos I. (20I5). Trampantojo: el diseño de espacios anamórficos. Trabajo de Fin de Grado en Fundamentos de la Arquitectura, Álvaro Tordesillas A., Alonso Rodríguez M. Universidad de Valladolid.

Sánchez Salinas D. (2019). Matte Painting: La geometría oculta del cine. Trabajo de Fin de Grado en Fundamentos de la Arquitectura, López Bragado D. Universidad de Valladolid.

\section{Authors}

Víctor-Antonio Lafuente Sánchez, Universidad de Valladolid, victorantonio.lafuente@uva.es

Daniel López Bragado, Universidad de Valladolid, daniel.lopez.bragado@uva.es

To cite this chapter. Lafuente Sánchez Víctor-Antonio, López Bragado Daniel (202I).Videomapping arquitectónico: la tecnología al servicio de la renovación del espacio/Architectural Videomapping: Technology at the Service of Space Renovation. In Arena A., Arena M., Mediati D., Raffa P. (a cura di). Connettere. Un disegno per annodare e tessere. Linguaggi Distanze Tecnologie. Atti del $42^{\circ}$ Convegno Internazionale dei Docenti delle Discipline della Rappresentazione/Connecting. Drawing for weaving relationship. Languages Distances Technologies. Proceedings of the 42th International Conference of Representation Disciplines Teachers. Milano: FrancoAngeli, pp. 2403-2420. 